\title{
Adsorption Isotherm Studies of Rhodamine B on Citrus sinesis Peel
}

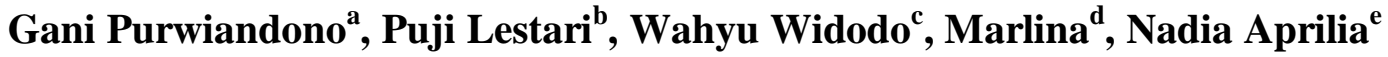 \\ ${ }^{a}$ Program Studi Kimia, Universitas Islam Indonesia \\ ${ }^{\mathrm{b}}$ Program Studi Teknik Lingkungan, Universitas Islam Indonesia \\ c,d,e Program Studi Pendidikan Kimia, Universitas Islam Indonesia \\ email: gani_purwiandono@uii.ac.id
}

\begin{abstract}
ABSTRAK
Telah dilakukan penelitian adsorpsi zat warna Rhodamin B pada biosorben kulit buah jeruk Medan (Citrus sinesis). Proses adsorpsi dilakukan pada $\mathrm{pH}$ netral selama 90 menit. Diketahui permukaan aktif biosorben kulit jeruk Medan sebesar $15 \mathrm{~m}^{2} / \mathrm{g}$ dan kerapatan $0,52 \mathrm{~g} / \mathrm{cm}^{3}$. Mekanisme adsorpsi Rhodamin B pada biosorben kulit jeruk Medan dilakukan dengan empat model adsorpsi, yaitu Langmuir, Freundlich, Temkin dan Dubinin-Radushkevich. Diperoleh mekanisme model adsorpsi Freundlich dengan nilai regresi paling tinggi yaitu 0,906 yang menyatakan interaksi adsorpsi zat warna Rhodamin B merupakan jenis interaksi multilayer pada permukaan biosorben.
\end{abstract}

Kata kunci: Rhodamin B, biosorben kulit jeruk Medan, isoterm adsorpsi Freundlich

\begin{abstract}
Adsorption of Rhodamine B on Citrus sinesis peel biosorbent has been conducted. The adsorption process was carried out in neutral $\mathrm{pH}$ for $90 \mathrm{~min}$. The active surface of the Citrus sinesis peel biosorbent was $15 \mathrm{~m}^{2} / \mathrm{g}$ and the density was $0.52 \mathrm{~g} / \mathrm{cm}^{3}$. The adsorption mechanism of Rhodamine B on Citrus sinesis peel biosorbent was studied using 4 adsorption model; Langmuir, Freundlich, Temkin, and Dubinin-Radushkevich. The adsorption fitted the Freundlich model with the regression value of 0.906. This indicates that the adsorption of Rhodamine B on the surface of Citrus sinesis peel biosorbent was a multilayer interaction.
\end{abstract}

Key Words: Rhodamine B, Citrus sinesis peel biosorbent, Freundlich adsorption isotherm

\section{Pendahuluan}

Limbah tekstil zat warna Rhodamin

B merupakan suatu permasalahan lingkungan yang dapat menyebabkan pencemaran air yang akan membahayakan biota di perairan. Berbagai metode telah dilakukan untuk mengurangi dampak limbah zat warna Rhodamin B, antara lain koagulasi dan flokulasi, reverse osmosis dan adsorpsi. Saat ini metode yang paling banyak digunakan adalah metode adsorpsi menggunakan adsorben karbon aktif (Raffatulah et al., 2010). Namun, pembuatan arang aktif membutuhkan perlakuan kimia lanjutan untuk meningkatkan permukaan aktif dan pori permukaan, sehingga diperlukan gagasan terkait material baru yang lebih murah, mudah serta mempunyai daya adsorpsi besar. Bahan-bahan alam organik yang mempunyai gugus hidroksil (-OH) dapat 
dipakai untuk mengadsorpsi ion-ion logam berat ataupun zat warna, khususnya limbah zat warna tekstil Rhodamin B (Hartono et al., 2005).

Pemanfaatan limbah pertanian sebagai biosorben zat warna telah banyak diteliti, salah satu limbah pertanian yang cukup potensial di Indonesia adalah limbah tanaman jeruk. Limbah kulit buah jeruk berpotensi menjadi adsorben dalam adsorpsi zat warna tekstil Rhodamin B (Raffatulah et al., 2010). Kulit jeruk yang dipakai dalam pembuatan adsorben pada penelitian ini, menggunakan kulit jeruk medan (Citrus sinesis). Penggunaan kulit jeruk medan karena jeruk medan merupakan jeruk lokal yang banyak dikonsumsi dan dijadikan sebagai produk minuman. Setelah buahnya dikonsumsi, kulit jeruk tersebut hanya dibuang tanpa dimanfaatkan kembali, sedangkan kulit jeruk berpontensi sebagai adsorben untuk menyerap limbah tekstil zat warna Rhodamin B. Kulit jeruk medan mengandung luas permukaan pori yang luas (Raffatulah et al., 2010). Sehingga pada penelitian ini dilakukan sintesis biosorben kulit jeruk dalam aktivitas adsorpsi limbah tekstil zat warna Rhodamin B. Mekanisme adsorpsi adsorbat pada permukaan adsorben dipelajari melalui empat model isoterm adsorpsi, yaitu isoterm adsorpsi Langmuir, Freundlich, Temkin dan DubininRadushkevich.

Isoterm adsorpsi Langmuir. Keseteimbangan adsorpsi adsorbat terjadi pada permukaan monolayer adsorben. Model isoterm Langmuir mengikuti persamaan: $\quad q_{e}=\frac{Q_{0} K_{L} C_{e}}{1+K_{L} C_{e}}, \quad$ persamaan tersebut dalam bentuk linier menjadi: $\frac{1}{q_{e}}=\frac{1}{Q_{0}}+\frac{1}{Q_{0} K_{L} C_{e}}, \quad$ dimana: $\quad c_{\mathrm{e}}$ adalah konsentrasi kesetimbangan dari adsorbat $(\mathrm{mg} / \mathrm{L}), \quad \mathrm{q}_{\mathrm{e}} \quad$ adalah konsentrasi kesetimbangan adsorbat zat teradsorp (mg/g), $\mathrm{Q}_{\mathrm{o}}$ adalah kapasitas maksimum monolayer $(\mathrm{mg} / \mathrm{g})$ dan $\mathrm{K}_{\mathrm{L}}$ adalah konstanta isoterm Langmuir. Nilai dari $\mathrm{q}_{\max }$ dan $\mathrm{K}_{\mathrm{L}}$ dihitung dari slope dan intersep grafik Langmuir $\frac{1}{q_{e}}$ versus $\frac{1}{\varepsilon_{e}}$ (Langmuir, 1918). Isoterm adsorpsi Freundlich. Merupakan karakteristik kesetimbangan adsorpsi pada permukaan heterogen (Hutson and Yang, 2010). Model isoterm adsorpsi Freundlich mengikuti persamaan: $Q_{e}=K_{f} C_{e}^{\frac{1}{n}}$, persamaan tersebut dalam bentuk linier menjadi $\log Q_{\theta}=\log K_{f}+\frac{1}{n} \log C_{\theta}, \quad$ dimana: $\mathrm{K}_{\mathrm{f}}$ 
adalah konstanta isotermal Freundlich $(\mathrm{mg} / \mathrm{g}), \mathrm{n}$ adalah intensitas adsorpsi, $\mathrm{c}_{\mathrm{e}}$ adalah konsentrasi kesetimbangan adsorbat (mg/L), dan $\mathrm{Q}_{\mathrm{e}}$ adalah jumlah adsorbat yang teradsorp dalam adsorben $(\mathrm{mg} / \mathrm{g})$.

Isoterm adsorpsi Temkin. Mendeskripsikan jenis atau faktor yang mempengaruhi interaksi antara adsorbenadsorbat (Tempkin and Pyzhev, 1940; Aharoni and Ungarish, 1977). Model isoterm adsorpsi Temkin mengikuti persamaan: $q_{e}=\frac{R T}{b} \ln \left(A_{T} C_{e}\right)$, persamaan tersebut dapat diubah dalam bentuk lain menjadi $\quad q_{e}=\frac{R T}{b} \ln A_{T}+\left(\frac{R T}{b}\right) \ln C_{e}$, diketahui $\quad B=\frac{R T}{b_{T}} \quad$ sehingga menjadi persamaan akhir $q_{e}=B \ln A_{T}+B \ln C_{\theta}$ dimana: $\quad \mathrm{A}_{\mathrm{T}}$ adalah konstanta kesetimbangan ikatan isoterm Temkin $(1,075 \mathrm{~L} / \mathrm{g}), \mathrm{b}_{\mathrm{T}}$ adalah konstanta isoterm Temkin, $\mathrm{R}$ adalah konstanta gas $(8,314$ $\mathrm{J} / \mathrm{mol} . \mathrm{K}), \mathrm{T}$ adalah temperatur, dan $\mathrm{B}$ adalah konstanta yang berhubungan dengan panas adsorpsi (25,34 J/mol).

\section{Isoterm Dubinin-Radushkevich.}

Mendeskripsikan mekanisme adsorpsi menggunakan distribusi energi Gaussian pada permukaan heterogen adsorben (Dabrowski, 2001; Dubinin, 1960). Model isoterm Dubinin-Radushkevich mengikuti persamaan: $\quad q_{\theta}=\left(q_{s}\right) \exp \left(-K_{a d s} \varepsilon^{2}\right)$, dalam bentuk lain menjadi $\ln q_{e}=\ln \left(q_{s}\right)-\left(K_{a d s} \varepsilon^{2}\right), \quad$ dimana $\quad \mathrm{Q}_{\mathrm{e}}$ adalah jumah adsorbat yang teradsorp dalam adsorben pada kesetimbangan $(\mathrm{mg} / \mathrm{g}), \mathrm{q}_{\mathrm{s}}$ adalah kapasitas isoterm teoritik $(\mathrm{mg} / \mathrm{g}), \quad \mathrm{K}_{\mathrm{ads}}$ adalah konstanta isoterm Dubinin-Radushkevich $\left(\mathrm{mol}^{2} / \mathrm{kJ}^{2}\right)$ dan $\varepsilon$ adalah nilai isoterm DubininRadushkevich.

\section{Tujuan Penelitian}

Tujuan dilakukan penelitian ini adalah mempelajari isoterm dan mekanisme adsorpsi zat warna Rhodamin B pada permukaan biosorben.

\section{Metode Penelitian}

Preparasi biosorben. Pada proses preparasi biosorben, kulit jeruk dicuci dan dibersihkan, dikeringkan dengan oven pada temperatur $120{ }^{0} \mathrm{C}$ selama 24 jam. Arang kulit jeruk dihancurkan dengan blender dan di ayak hingga menjadi serbuk, dilanjutkan dengan aktivasi kimia dengan $\mathrm{HNO}_{3}$ dengan perbandingan massa biosorben : massa $\mathrm{HNO}_{3}=1: 1$. Campuran diaduk dan dikeringkan menggunakan oven. Selanjutnya dicuci kembali dengan aquades panas, ditambah $\mathrm{NaOH}$ hingga $\mathrm{pH}$ biosorben netral. 
Permukaan aktif spesifik. kerapatan $=\frac{w_{2}-w_{1}}{v}, \quad$ dengan Digunakan metode Saers untuk $w_{2}$ merupakan berat silinder dengan menghitung permukaan aktif spesifik (Saer, 1956; Shawabkeh and Tutunji, 2003). Sebanyak 0,5 g biosorben diasamkan dengan $\mathrm{HCl} 0,1 \mathrm{M}$ hingga $\mathrm{pH}$ 3-3,5. Dimasukkan biosorben dalam $50 \mathrm{~mL}$ akuades dan ditambahkan $10 \mathrm{~g} \quad \mathrm{NaCl}$. Dilakukan titrasi dengan larutan standar $\mathrm{NaOH}$ 0,1 M hingga pH berubah dari $4 \mathrm{ke}$ 9. Volume yang dibutuhkan untuk menaikkan $\mathrm{pH}$ dari 4 ke 9 dicatat dan permukaan aktif spesifik dihitung menggunakan persamaan $S\left(\frac{m^{2}}{g}\right)=32 v-25 . \quad$ Asumsi bahwa permukaan aktif spesifik merupakan daerah tempat adsorbat teradsorp pada permukaan adsorben.

\section{Perhitungan kerapatan biosorben}

(bulk density). Digunakan prinsip Archimedes dengan menggunakan variasi silinder berlubang yang diisi dan dievaluasi sebelum dan sesudah diisi oleh biosorben. Silindir dimasukkan dalam wadah berisi air, volume air yang hilang dalam wadah merupakan selisih antara berat silinder yang kosong dan berat silinder yang diisi oleh biosorben. Perhitungan kerapatan biosorben dihitung dengan persamaan sampel, $w_{1}$ berat silinder kosong dan $\mathrm{v}$ merupakan volume silinder.

Uji adsorpsi. Ditambahkan 0,5 g biosorben dalam larutan $100 \mathrm{ml}$ dengan variasi konsentrasi $10 \mathrm{mg} / \mathrm{L}$ - $50 \mathrm{mg} / \mathrm{L}$ Rhodamin B hingga mencapai kesetimbangan adsorpsi selama 90 menit. Campuran kemudian dianalisis menggunakan UV-Vis (Hitachi 2010). Jumlah zat teradsorp (mg/L) dihitung menggunakan persamaan: (Vanderborght andVan Grieken, 1977).

$Q=\frac{v\left(c_{i}-c_{e}\right)}{w}$, dimana $\mathrm{Q}$ adalah jumlah zat yang teradsorp dalam larutan, v adalah volume adsorbat, $\mathrm{C}_{\mathrm{i}}$ adalah konsentrasi sebelum adsorpsi, $\mathrm{C}_{\mathrm{e}}$ adalah konsentrasi setelah adsorpsi dan w adalah berat adsorben. Data yang diperoleh dicocokan dengan isoterm: Langmuir, Freundlich, Temkin, dan DubininRadushkevich (Igwe dan Abia, 2006).

\section{Pembahasan}

Karakter sifat biosorben kulit jeruk dievalusi dalam tabel parameter fisikakimia pada Tabel 1. Pada tabel tersebut diketahui bahwa karakter permukaan aktif adsorben yang paling berpengaruh 
terhadap proses adsorpsi zat warna Rhodamin B dengan nilai $15\left(\mathrm{~m}^{2} / \mathrm{g}\right)$.

Model adsorpsi biosorben kulit jeruk dengan zat warna Rhodamin B dilakukan dengan mengikuti model isoterm adsorpsi Langmuir, Freundlich, Temkin dan Dubinin-Radushkevich. Tabel 2 menunjukkan nilai beberapa parameter yang digunakan dalam model adsorpsi.

Tabel 1. Parameter Fisika-Kimia Biosorben Kulit Jeruk

\begin{tabular}{|c|c|}
\hline Sifat & Biosorben Kulit Jeruk \\
\hline $\mathrm{pH}$ & $7,0-7,5$ \\
\hline Permukaan aktif (surface area) & $15\left(\mathrm{~m}^{2} / \mathrm{g}\right)$ \\
\hline Kerapatan (bulk density) & $0,52\left(\mathrm{~g} / \mathrm{cm}^{3}\right)$ \\
\hline
\end{tabular}

Tabel 2. Parameter Model Adsorpsi Zat Warna Rhodamin B Dalam Bisorben Kulit Jeruk

\begin{tabular}{|c|c|c|c|c|c|c|c|c|c|c|c|}
\hline No & $\begin{array}{c}\mathrm{C}_{\mathrm{o}} \\
(\mathrm{mg} / \mathrm{L})\end{array}$ & $\begin{array}{c}\mathrm{C}_{\mathrm{e}} \\
(\mathrm{mg} / \mathrm{L})\end{array}$ & $1 / \mathrm{C}_{\mathrm{e}}$ & $\log \mathrm{C}_{\mathrm{e}}$ & $\begin{array}{c}\mathrm{Ln} \\
\mathrm{C}_{\mathrm{e}}\end{array}$ & $\begin{array}{c}\mathrm{Q}_{\mathrm{e}} \\
(\mathrm{mg} / \mathrm{g})\end{array}$ & $1 / \mathrm{Q}_{\mathrm{e}}$ & $\begin{array}{c}\mathrm{Log} \\
\mathrm{Q}_{\mathrm{e}}\end{array}$ & $\begin{array}{c}\mathrm{Ln} \\
\mathrm{Q}_{\mathrm{e}}\end{array}$ & $\begin{array}{c}\mathrm{C}_{\mathrm{e}} / \mathrm{Q}_{\mathrm{e}} \\
(\mathrm{g} / \mathrm{L})\end{array}$ & $\varepsilon^{2}$ \\
\hline 1 & 10 & 1,1 & 0,91 & 0,04 & 0,10 & 2,60 & 0,38 & 0,41 & 0,96 & 0,42 & $1,20 \mathrm{E}+05$ \\
\hline 2 & 20 & 4,5 & 0,22 & 0,65 & 1,50 & 3,42 & 0,29 & 0,53 & 1,23 & 1,32 & $4,13 \mathrm{E}+04$ \\
\hline 3 & 30 & 10,4 & 0,10 & 1,02 & 2,34 & 6,72 & 0,15 & 0,83 & 1,91 & 1,55 & $3,12 \mathrm{E}+04$ \\
\hline 4 & 40 & 12,3 & 0,08 & 1,09 & 2,51 & 7,65 & 0,13 & 0,88 & 2,03 & 1,61 & $1,24 \mathrm{E}+04$ \\
\hline 5 & 50 & 25,5 & 0,04 & 1,41 & 3,24 & 8,13 & 0,12 & 0,91 & 2,10 & 3,14 & $1,10 \mathrm{E}+04$ \\
\hline
\end{tabular}

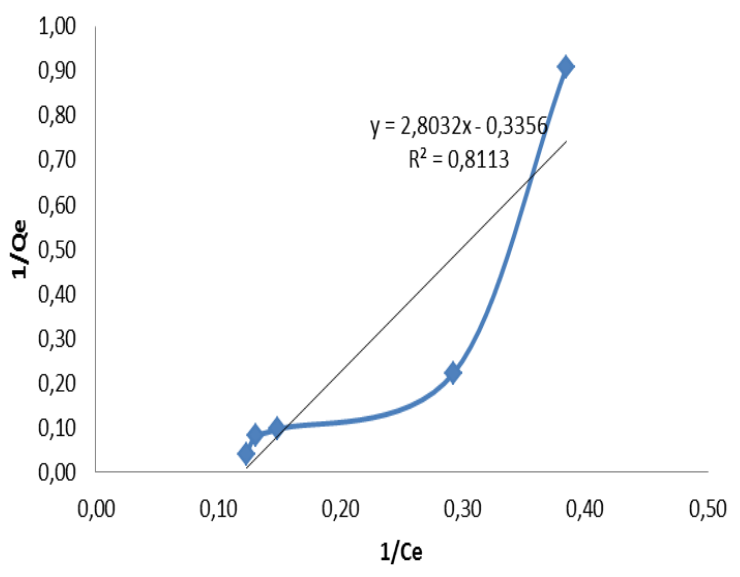

Gambar 1. Model Isoterm Adsorpsi Langmuir

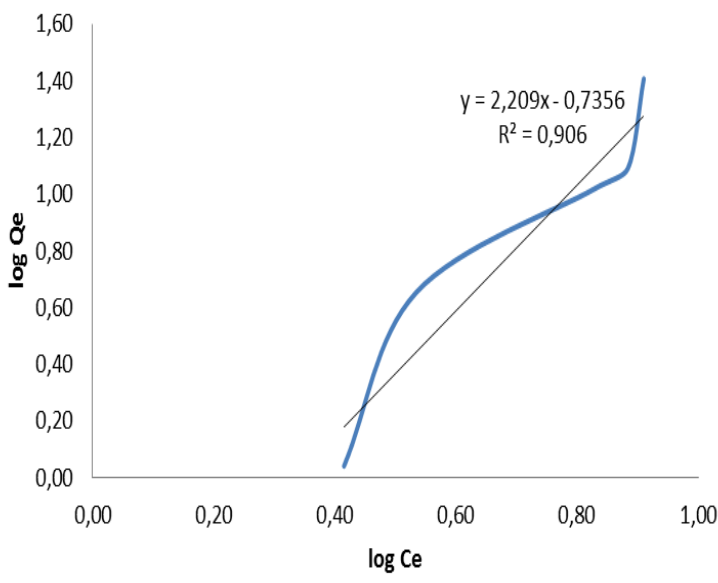

Gambar 2. Model Isoterm Adsorpsi Freundlich 


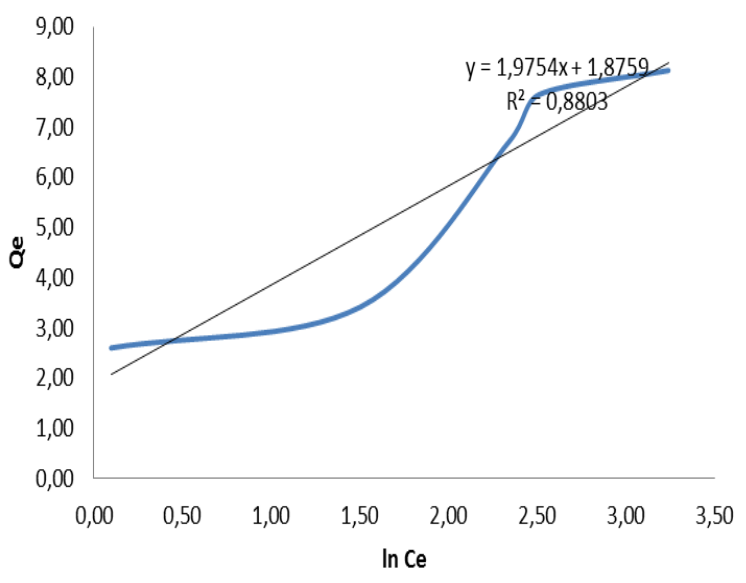

Gambar 3. Model Isoterm Adsorpsi Temkin

Data isoterm adsorpsi Langmuir, Freundlich, Temkin dan DebininRadushkevich menunjukkan nilai regresi tertinggi persamaan kurva model adsorpsi terdapat pada kurva model adsorpsi Freudlich. Model ini menunjukkan bahwa interaksi adsorbat pada permukaan adsorben melalui mekanisme multilayer dengan interaksi sekunder antara molekul zat warna Rhodamin B pada permukaan biosorben. Zat warna Rhodamin B berinteraksi sekunder dengan permukaan biosorben kulit jeruk melalui molekul lignin-selulosa.

\section{Kesimpulan}

Kesimpulan dari hasil penelitian menunjukkan kesetimbangan adsorpsi zat warna Rhodamin B dalam biosorben kulit jeruk pada temperatur $25^{\circ} \mathrm{C}$ dan $\mathrm{pH}$ antara 7,0-7,5 mengikuti model adsorpsi Freundlich.

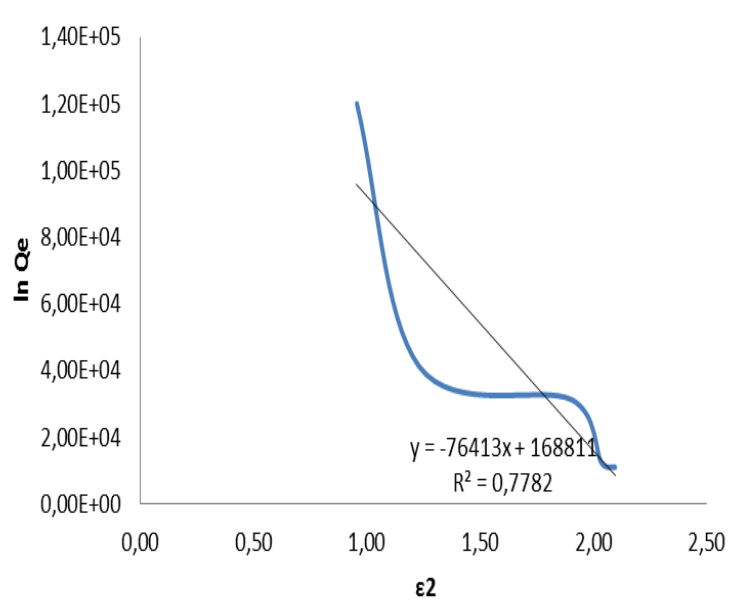

Gambar 4. Model Isoterm Adsorpsi Dubinin-Radushkevich

\section{Ucapan Terimakasih}

Penulis mengucapkan terima kasih kepada DPPM (Direktorat Penelitian dan Pengabdian Masyarakat) Universitas Islam Indonesia atas pendanaan penelitian ini.

\section{Pustaka}

Aharoni, C., and Ungarish, M., 1977. Kinetics of activated chemisorption. Part 2. Theoretical models, J. Chem. Soc. Faraday Trans. 73. 456-464

Dabrowski, A., 2001. Adsorption from theory to practice, Adv. Colloid Interface Sci. 93, 135-224

Dubinin, M.M., 1960. The potential theory of adsorption of gases and vapors for adsorbents with energetically nonuniform surface, Chem. Rev. 60, 235266

Hartono, S.B., Ismadji, S., Sudaryanto, Y., Irawaty, W., 2005. Utilization of Teak Sawdust From Timber Industry as Precursor of Activated Carbon Preparation For Removal Of Dyes From Synthetic Effluent. J. Ind. England Chemistry. 11 (6), 864-869 
Hutson, N.D., and Yang, R.T., 2000 ADSORPTION, Colloid Interf Sci., pp 189

Igwe, J.C., and Abia, A.A., 2006. A bioseparation process for removing heavy metals from waste water using biosorbents, African Journal of Biotechnology, 5 (12), 1167-1179

Langmuir, I., 1918. The adsorption of gases on plane surfaces of glass, mica and platinum, J. Am. Chem. Soc. 40, 13621403

Raffatulah, M., Sulaiman, O., Hashim, R., Ahmad, A., 2010. Adsorption of methylene blue on low-cost adsorbent: a review. J. Chem. Eng. 177, 7080

Saer, G.W., 1956. Determination of Specific surface area of sodium hydroxide, J. Anal. Chem. 28(2), 1981-1983

Shawabkeh, R.A., and Tutunji, M.F., 2003. Experimental studies and modeling of the basic dye sorption by diamaceous clay, Applied Clay Sci. 24, 111-114

Tempkin, M.I., and Pyzhev, V., 1940. Kinetics of ammonia synthesis on promoted iron catalyst, Acta Phys. Chim. USSR 12, 327-356

Vanderborght, M., and Van Grieken, E., 1977. Enrichment of trace metals in water by adsorption on activated carbon, Anal. Chem, 49(2). 311-316 